\title{
As relações entre a Univasf e a agricultura familiar por meio do Programa Institucional de Bolsas de Extensão (Pibex)
}

Renata Cristina de Sá Barreto Freitas ${ }^{1}$, Helder Freitas ${ }^{2}$, Denes Dantas Vieira ${ }^{3}$

\begin{abstract}
Resumo
O propósito deste trabalho é compreender as relações, os limites e as possibilidades de intervenções das ações de extensão universitária da Universidade Federal do Vale do São Francisco (Univasf) junto a agricultores familiares nos territórios de atuação no Semiárido Brasileiro (SAB), região do Vale do Submédio São Francisco. A partir do mapeamento dos projetos de extensão mantidos pela Univasf, executados pelo Programa Institucional de Bolsas de Extensão (Pibex) nos editais anuais de 2016, 2017 e 2018, este estudo analisou os processos de intervenção sociotécnica junto a agricultores familiares e comunidades rurais. Utilizando-se de métodos qualitativos e quantitativos, a pesquisa demonstrou que as iniciativas voltadas para o meio rural são reduzidas quando comparadas às iniciativas para as áreas urbanas. Em relação ao enfoque da interação com os agricultores familiares, identificou-se que, entre os projetos Pibex, há um predomínio de iniciativas de extensão universitária orientadas pelo enfoque difusionista, algumas ações com características assistencialistas e uma tendência em direção à adoção de metodologias participativas. De maneira geral, conclui-se que as ações de extensão universitária do Pibex, mesmo manifestando diferentes enfoques e níveis de interação, têm possibilitado a troca de saberes por meio da interação entre estudantes, docentes e comunidades rurais.
\end{abstract}

\section{Palavras-chave}

Desenvolvimento rural sustentável. Extensão universitária. Metodologias extensionistas.

\footnotetext{
${ }^{1}$ Mestra em Extensão Rural pela Universidade Federal do Vale do São Francisco, Pernambuco, Brasil; jornalista da Assessoria de Comunicação Social da Universidade Federal do Vale do São Francisco, Pernambuco, Brasil. E-mail: renata.bfreitas@univasf.edu.br.

${ }^{2}$ Doutor em Solos pela Universidade Federal de Viçosa, Minas Gerais, Brasil; professor adjunto na Universidade Federal do Vale do São Francisco, Pernambuco, Brasil. E-mail: helder.freitas@univasf.edu.br.

${ }^{3}$ Doutor em Ciências Sociais pela Universidade Federal do Rio Grande do Norte, Brasil; professor da Universidade Federal do Vale do São Francisco, Bahia, Brasil; membro do Grupo de Pesquisa e Extensão Sertão Agroecológico. E-mail: denes.vieira@univasf.edu.br.
} 


\title{
The relationships between Univasf and family farmers through the Institutional Program of Extension Grants (Pibex)
}

\author{
Renata Cristina de Sá Barreto Freitas ${ }^{4}$, Helder Freitas ${ }^{5}$, Denes Dantas Vieira ${ }^{6}$
}

\begin{abstract}
The purpose of this work is to understand the relationships, limits and possibilities of interventions of the University Extension actions of Universidade Federal do Vale do São Francisco (Univasf) with family farmers in the territories of action, in the Brazilian Semiarid (SAB), region of the São Francisco Sub-medium Valley. Based on a mapping of the extension projects maintained by Univasf executed by the Institutional Program of Extension Grants (Pibex) in the annual calls for proposals of 2016, 2017 and 2018, this study analyzed the processes of socio-technical intervention with family farmers and rural communities. Using qualitative and quantitative methods, the research showed that initiatives aimed at the rural areas are reduced when compared to those for urban areas. With regard to the focus on interaction with family farmers, it was identified that among the Pibex projects, there is a predominance of university extension initiatives guided by the diffusionist approach, some actions with welfare characteristics and a tendency towards the adoption of participatory methodologies. In general, it is concluded that the actions of university extension of Pibex, even though they manifest different approaches and levels of interaction, have enabled the exchange of knowledge through interaction between students, professors and rural communities.
\end{abstract}

\section{Keywords}

Sustainable rural development. University extension. Extensionist methodologies.

\footnotetext{
${ }^{4}$ Master in Rural Extension, Federal University of São Francisco Valley, State of Pernambuco, Brazil; journalist of the Social Communication Office in the same institution. E-mail: renata.bfreitas@univasf.edu.br.

${ }^{5} \mathrm{PhD}$ in Soils, Federal University of Viçosa, State of Minas Gerais, Brazil; assistant professor at the Federal University of São Francisco Valley, State of Pernambuco, Brazil. E-mail: helder.freitas@ univasf.edu.br.

${ }^{6} \mathrm{PhD}$ in Social Sciences, Federal University of Rio Grande do Norte, Brazil; professor at the Federal University of São Francisco Valley, State of Bahia, Brazil; member of the Sertão Agroecológico Research and Extension Group. E-mail: denes.vieira@univasf.edu.br.
} 


\section{Introdução}

Ao longo da constituição das universidades brasileiras, o tripé ensino, pesquisa e extensão consolidou-se como base da atuação dessas instituições junto à sociedade. Desde o surgimento das primeiras universidades no Brasil, o ensino é reconhecido como sua principal dimensão e função. Com o desenvolvimento científico e tecnológico, a pesquisa também foi incorporada e reconhecida socialmente como outra importante dimensão de atuação da universidade brasileira. A extensão universitária, apesar de ainda ser considerada a dimensão mais frágil desse tripé, vem ganhando espaço e reconhecimento institucional e social nas últimas décadas.

A atividade de extensão das universidades brasileiras, principalmente as públicas, vem estabelecendo relações e vínculos com a comunidade a ponto de promover o fortalecimento também do ensino e da pesquisa. A extensão universitária tem se constituído, em muitos casos, como uma via de mão de dupla, por meio da qual a universidade contribui para a resolução e o apoio às demandas e questões vivenciadas pelas comunidades, ao mesmo tempo em que sistematizam, constroem e interagem com novos saberes.

Um marco na institucionalização da extensão universitária no Brasil foi a criação do Fórum de Pró-Reitores de Extensão das Universidades Públicas Brasileiras (Forproex), no final da década de 1980, durante o período de redemocratização do país. De acordo com síntese elaborada pelo Forproex, a extensão é definida como "processo educativo, cultural e científico que articula o ensino e a pesquisa de forma indissociável e viabiliza a relação transformadora entre Universidade e Sociedade” (Forproex, 2012, p. 9).

A extensão universitária tem hoje uma dimensão mais ampla e voltada para a intervenção e interação das universidades brasileiras com a sociedade, frente à sua responsabilidade na superação das desigualdades sociais e promoção da democracia. Cabe a ela estabelecer e manter relações com a sociedade, visando aproximar a Universidade da população e possibilitar a troca de informações e conhecimentos entre a comunidade acadêmica e o público, favorecendo a emancipação da sociedade. É pela extensão que ocorre a interação entre o saber científico e o saber popular, pela articulação com ensino e pesquisa (OLIVEIRA; OLIVEIRA; VIEIRA, 2018).

Muitos desafios ainda estão postos no cenário futuro da extensão no país, entretanto, diversos mecanismos legais vêm assegurando sua consolidação, especialmente nas Instituições 
Federais de Ensino Superior (Ifes). Dentre eles, cabe destacar a Constituição Federal de 1988, a Lei de Diretrizes e Bases da Educação Nacional (LDB, 1996), o Plano Nacional de Educação (PNE, 2014), a Política Nacional de Extensão Universitária (Pneu, 2012), e, mais recentemente, as Diretrizes para as Políticas de Extensão da Educação Superior Brasileira (2018).

A atividade extensionista na Univasf é regulamentada pela Resolução no 4/2017, do Conselho Universitário (Conuni) e sua execução é acompanhada pela Câmara de Extensão, órgão consultivo e deliberativo formado por docentes, técnico-administrativos e discentes e presidido pelo titular da Pró-Reitoria de Extensão (Proex).

Em 2018, de acordo com a Proex, foram executados 61 projetos de extensão por meio do Pibex. Também foram executados outros programas especiais financiados em parceria com ministérios e órgãos de fomento diversos e vinculados à Proex. Dentre esses, pode-se destacar o projeto "Inovando Práticas: Transformando Vidas", o Centro de Recondicionamento de Computadores (CRC-Univasf) e os Núcleos Descentralizados de Extensão dos campi (OLIVEIRA; OLIVEIRA; VIEIRA, 2018).

Este trabalho se detém sobre a atuação da Univasf na extensão universitária junto a agricultores familiares, por meio do Programa Institucional de Bolsas de Extensão (Pibex) no período de 2016 a 2018, e apresenta informações e reflexões pertinentes à relação Universidade-Sociedade. Tais reflexões podem contribuir para a análise das ações e do papel da ação extensionista das universidades, bem como o aprimoramento de políticas e programas institucionais de extensão universitária. Espera-se que este trabalho também possa contribuir com o processo de efetivação da atuação extensionista na Univasf a partir das novas determinações legais estabelecidas pelas Diretrizes para as Políticas de Extensão da Educação Superior Brasileira ${ }^{7}$.

\section{Histórico e contextualização das iniciativas extensionistas na Univasf}

Ações extensionistas começaram a ser executadas na Univasf por meio de iniciativas de docentes mesmo antes do processo de regulamentação interna da extensão universitária. As

\footnotetext{
7 As Diretrizes para as Políticas de Extensão da Educação Superior Brasileira foram estabelecidas pelo Ministério da Educação (MEC), por meio da Portaria $n^{\circ} 1.350$, publicada no Diário Oficial da União (DOU), em 17 de dezembro de 2018. As universidades têm até o final de 2021 para se adequar às determinações.
} 
primeiras iniciativas se deram a partir de projetos aprovados junto a órgãos de fomento e também por meio das atividades dos Núcleos Temáticos (NT), que se propõem a articular atividades de ensino, pesquisa e extensão e valorizar a interação de docentes e estudantes com a comunidade externa.

Nos anos iniciais da Univasf, um importante projeto de fomento à extensão, articulado pela então Pró-Reitoria de Integração (Proin) foi o Programa Conexões de Saberes, financiado pelo Ministério da Educação (MEC), tendo realizado suas atividades entre 2006 e 2010. No primeiro ano, foram desenvolvidos 13 projetos de pesquisa e extensão com a participação de 25 bolsistas e 12 docentes. O Conexões de Saberes teve grande destaque institucional por incentivar a participação dos universitários de baixa renda a atuar em suas comunidades, integrando a Univasp com as populações locais (SANTIAGO, 2008).

Outro importante programa de fortalecimento da Univasf, também considerado relevante para a consolidação da extensão no país, foi o Programa de Extensão Universitária (Proext/MEC). Financiado pelo MEC por meio de editais anuais, em parceria com o Ministério da Cultura (MinC) e o Forproex (INCROCCI; ANDRADE, 2017), o programa contemplou iniciativas extensionistas da Univasf em diferentes áreas, destinando recursos para bolsas e infraestrutura. O Proext foi encerrado em 2016, ano em que foi lançado seu último edital e, apesar de alguns projetos aprovados, não foram repassados recursos para a execução das atividades.

Em 2006, numa iniciativa própria de fomento à extensão universitária, a Univasf criou o Programa Institucional de Bolsas de Integração (Pibin), que, em 2012, foi substituído pelo Programa Institucional de Bolsas de Extensão (Pibex). No primeiro ano de execução do Pibin, em 2006, 23 projetos foram submetidos ao edital de seleção e dez foram aprovados e contemplados com uma bolsa para os estudantes envolvidos nas ações. Nas três primeiras edições, do Pibin, no período de 2006 a 2008, foram executados 46 projetos, que possibilitaram o envolvimento de 278 estudantes, entre bolsistas e voluntários, e de 106 docentes e geraram a produção de 75 publicações científicas. Deste total de iniciativas, seis tinham como foco o meio rural e a agricultura familiar (SANTIAGO, 2008).

Os agricultores que foram contemplados com as ações de extensão voltadas para o desenvolvimento rural integram diferentes comunidades tradicionais e vivem, em sua maioria, em áreas acometidas pela seca, desenvolvendo atividades agropecuárias e extrativistas 
adaptadas à realidade da baixa precipitação e escassez de água. Segundo o Censo Agropecuário 2006 (IBGE, 2006), havia aproximadamente 1,3 milhão de estabelecimentos de agricultura familiar com produção no semiárido, sendo que $77 \%$ desenvolvem atividades agropecuárias, com destaque para produção animal (61,6\%), horticultura $(7,9 \%)$, extração vegetal $(6,6 \%)$ e agroindústria $(2,9 \%)$.

Neste cenário, a Univasf atua no Semiárido Brasileiro (SAB), na região do Vale do Submédio São Francisco, na qual grande parte da população constitui-se por agricultores familiares ${ }^{8}$, que integram diferentes categorias sociais, com destaque para as comunidades tradicionais em suas diferentes manifestações, como povos indígenas, quilombolas e assentados de projetos de reforma agrária. Também se encontram iniciativas de agricultura urbana e periurbana (SIQUEIRA, 2017; BARROSO; CAPUXO; FREITAS, 2017). Nos perímetros irrigados, que transformaram o Vale do São Francisco, especialmente a região de Petrolina (PE) e Juazeiro (BA), no maior polo fruticultor irrigado do Brasil, há ainda os colonos e pequenos empreendedores irrigantes e os grandes exportadores de frutas (LEÃO; MOUTINHO, 2014; SILVA; SILVA, 2016).

É nesta região, reconhecida pela importância socioambiental e econômica da população e de seus territórios rurais, que a Univasf desenvolve as atividades acadêmicas de ensino, pesquisa e extensão e onde são realizadas as ações extensionistas do Pibex, sobre as quais este trabalho se detém para compreender a ação extensionista da Universidade junto à agricultura familiar.

\section{Percurso metodológico na investigação da ação extensionista}

A primeira etapa do trabalho constituiu-se de uma revisão bibliográfica, seguida por análise documental, realização de entrevistas semiestruturadas, sistematização e análise dos dados. Foram analisados os projetos do Pibex, aprovados e implementados pela Univasf por meio dos editais lançados anualmente para os anos de 2016, 2017 e 2018. Este levantamento possibilitou mapear as ações de extensão universitária no âmbito do Pibex durante o triênio.

A partir dos dados dos projetos e relatórios de atividades, foram compilados os principais

\footnotetext{
${ }^{8}$ A Lei da Agricultura Familiar (Lei $\mathrm{N}^{\circ}$ 11.326/2006) considera como agricultores familiares aqueles agricultores que praticam atividades no meio rural utilizando, predominantemente, mão de obra da família, entre outros pré-requisitos, e também determina que se enquadram nesta categoria os silvicultores, aquicultores, extrativistas, pescadores, povos indígenas, integrantes de comunidades quilombolas e demais povos e comunidades tradicionais.
} 
proponentes dos projetos de extensão, número de participantes que se envolveram com as ações, população beneficiada e local de realização das atividades, se no espaço urbano ou rural, entre outras informações. Com estes dados, fez-se uma primeira triagem, a partir da qual se determinou a amostra universal desta pesquisa, composta pelos projetos de extensão universitária cujas ações foram direcionadas à agricultura familiar nos três anos estudados. Foram selecionados projetos com abordagens identificadas como difusionista e participativa na fase de análise documental (projeto submetido e relatórios de atividades) desenvolvidos no universo temporal de análise. Essa estratificação orientou o processo de entrevista e análise dos resultados obtidos ao longo da pesquisa.

As entrevistas do tipo semiestruturadas foram realizadas individualmente entre fevereiro e maio de 2019. Participaram desta etapa sete projetos apoiados pelo Pibex, contemplando as seguintes características: projetos realizados no período de 2016 a 2018, direcionados às comunidades de agricultores familiares, com tempos de duração diferentes (um ano, dois anos ou mais) e que representam abordagens metodológicas distintas de extensão rural em suas propostas de trabalho.

Foram realizadas entrevistas com sete docentes, que coordenaram os projetos, além de sete estudantes e sete agricultores familiares, obtendo a participação equilibrada dos três segmentos envolvidos nas ações e contemplando projetos tanto com abordagens difusionistas quanto participativas, mapeadas na análise documental. Também foram ouvidos representantes de duas instituições, uma governamental e outra não governamental que atuaram como parceiras nas iniciativas de extensão universitária junto a agricultores familiares. No total, foram realizadas entrevistas com 23 pessoas. Foi preservado o anonimato de todos os entrevistados, que assinaram Termo de Consentimento Livre e Esclarecido $(\text { TCLE })^{9}$, e a identificação de cada um deles no trabalho deu-se de acordo com a categoria em que se classifica (docente, estudante, agricultor familiar ou parceiro) seguido do uso de números de 1 a 7.

Na coleta e sistematização dos dados da pesquisa de campo, foi utilizada a técnica de triangulação, por meio da qual é possível observar e analisar diferentes aspectos do fenômeno social estudado. A triangulação envolve, de acordo com Triviños (1987), três enfoques que devem ser considerados. São os processos que estão centrados no sujeito; elementos

\footnotetext{
${ }^{9}$ Todos os entrevistados assinaram Termo de Consentimento Livre e Esclarecido (TCLE): CAEE $\mathrm{N}^{\circ}$ 99838818.8.0000.5196.
} 
produzidos pelo meio do sujeito, a exemplo de documentos e fotografias; e processos e produtos originados pelo ambiente onde está inserido o sujeito. A triangulação permite, portanto, a observação e compreensão do fenômeno social em sua complexidade e dentro de seu contexto. Nesse sentido, foram confrontados os dados obtidos com as informações analisadas anteriormente à realização da pesquisa e o arcabouço teórico da extensão universitária.

\section{O que revelam os números do Pibex: mapeando a ação extensionista da Univasf}

Desde que foi instituído, em 2012, o Pibex tem oferecido, anualmente, bolsas para estudantes regularmente matriculados nos cursos de graduação. Entre 2013 e 2018, como mostra a Figura 1, constatou-se uma tendência de aumento no número de projetos aprovados com bolsa no âmbito do Pibex, exceto em 2015 e 2017, quando foram observadas reduções no número de aprovações, devido a períodos de contingenciamento orçamentário por parte do governo federal.

Figura 1 - Evolução do número de projetos aprovados com bolsas Pibex (2013 a 2018)

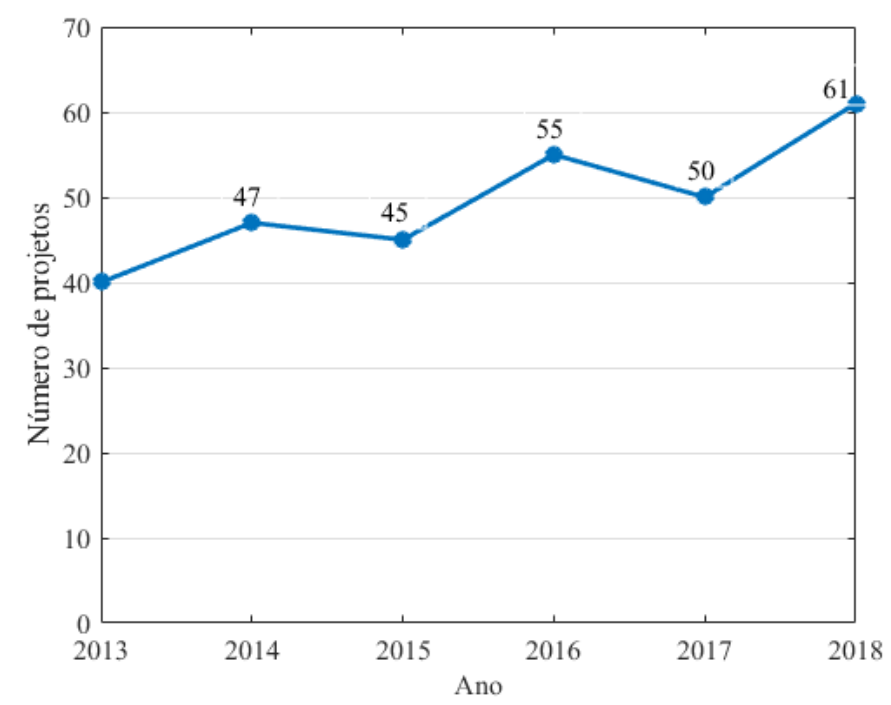

Fonte: Os autores (2019) baseados nos dados da Direx/Proex.

Os dados referentes à execução do Pibex foram sistematizados de modo a evidenciar o número de pessoas envolvidas na execução das atividades extensionistas no Pibex no triênio de análise (Figura 2). Constituem-se como integrantes das equipes executoras as categorias de bolsistas, voluntários e profissionais. 
Figura 2 - Número de participantes dos projetos do Pibex $(2016,2017$ e 2018)

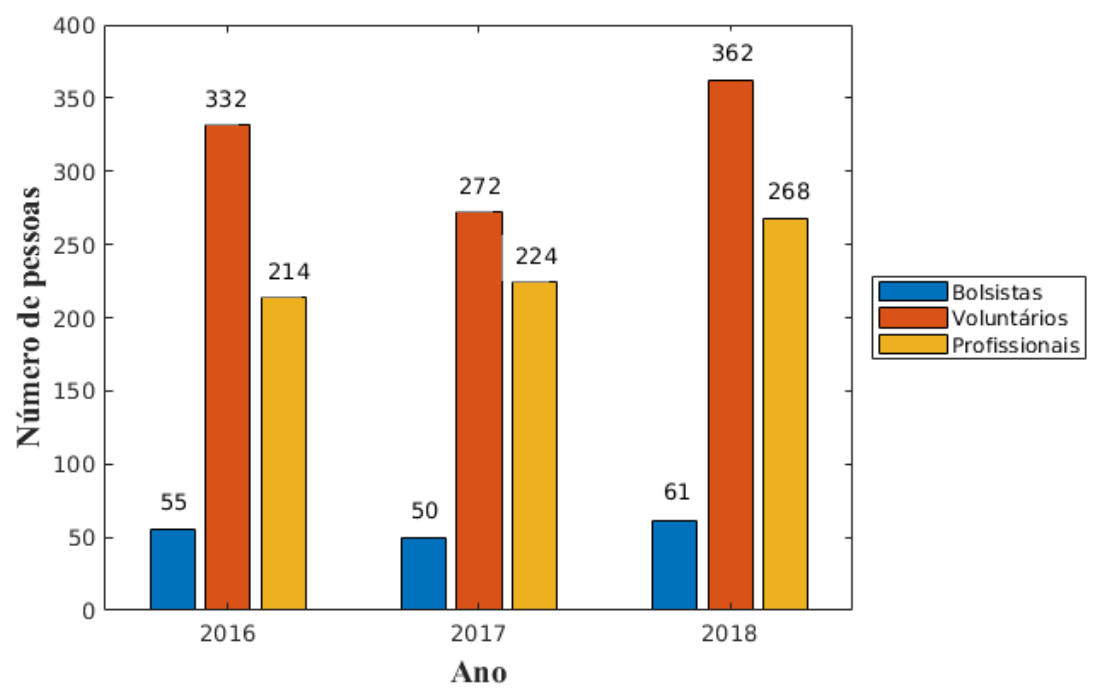

Fonte: Os autores (2019) baseados nos dados da Direx/Proex.

Os dados demonstram que o número de estudantes e profissionais envolvidos nas atividades extensionistas vem crescendo a cada edição. Embora tenha se verificado uma redução no número de estudantes voluntários em 2017, com recuperação em 2018 (Figura 2), essa categoria se constituiu a mais numerosa entre os envolvidos nos projetos de extensão, dado que o número de estudantes que buscam se engajar nas ações extensionistas tem sido maior do que o número de bolsas disponibilizadas nos editais de extensão da Univasf. Esse também é o comportamento da evolução no número de estudantes bolsistas, cuja redução em 2017 pode ser atribuída a contingenciamentos orçamentários do governo federal.

A análise geral do perfil das equipes demonstra que, em alguns projetos, há equipes multidisciplinares, que contam com a participação de colaboradores de outras instituições e entidades parceiras, com formação em áreas diversas, que são contabilizados na Figura 2 entre os profissionais. Alguns destes aparecem como colaboradores em mais de um projeto de extensão devido à sua vinculação institucional e parceria com várias iniciativas de extensão universitária.

O envolvimento na extensão por meio do universo de análise do Pibex teve a participação de $16 \%$ do total de estudantes e aproximadamente $27 \%$ do total de servidores no período analisado. Apesar de ser um percentual considerável de participação discente e docente na atividade extensionista do Pibex na Univasf, ainda há muito que se avançar no envolvimento 
da comunidade acadêmica com a população dos territórios onde a Universidade se faz presente.

Mesmo com uma participação que necessita ser ampliada, os projetos de extensão universitária da Univasf já beneficiaram uma população expressiva das comunidades. $\mathrm{O}$ universo da população beneficiada variou muito no período analisado. A maior quantidade de pessoas beneficiadas pelas ações foi em 2016, ano em que, de acordo com os dados dos relatórios compilados, os 55 projetos alcançaram 439.032 pessoas. Nesse caso, um único projeto indicou uma população de 400 mil habitantes de municípios circunvizinhos como público beneficiado pelas ações, pois se tratava de um programa de rádio. Em 2017, estima-se que 24.536 pessoas tenham sido beneficiadas pelos 50 projetos e, em 2018, 61 ações beneficiaram 37.917 pessoas. Verificou-se que o público contemplado pelas iniciativas extensionistas foi diversificado, com ações para diferentes faixas etárias, beneficiando crianças, jovens, adultos e idosos.

\section{O Pibex e a extensão universitária da Univasf junto à agricultura familiar}

A maioria dos projetos Pibex atuou junto à população da zona urbana, mas constata-se que há uma tendência de aumento no número de projetos, estudantes envolvidos e população beneficiada por esses projetos no espaço rural (Tabela 1). Os dados mostram que, em média, anualmente $20 \%$ dos projetos Pibex atuaram junto às comunidades rurais. Entretanto, apenas uma parte dos projetos foi desenvolvida junto à agricultura familiar. Alguns trabalharam com escolas rurais e com comunidades rurais em geral, mas não diretamente com o foco nos agricultores familiares.

Tabela 1 - Dados dos projetos Pibex direcionados ao público do meio rural no triênio 20162018

Projetos Pibex

\begin{tabular}{ccccc}
\hline Ano & Total de projetos & Projetos no rural & $\begin{array}{c}\text { Estudantes } \\
\text { envolvidos }^{10}\end{array}$ & $\begin{array}{c}\text { População } \\
\text { beneficiada }\end{array}$ \\
\hline 2016 & 55 & 11 & 49 & 2.087 \\
2017 & 50 & 13 & 54 & 5.361 \\
2018 & 61 & 14 & 82 & 4.229
\end{tabular}

Fonte: Os autores (2019) baseados nos dados da Direx/Proex.

\footnotetext{
${ }^{10}$ Inclui bolsistas e voluntários. 
No triênio analisado, a Univasf apoiou 38 projetos, de um total de 166 iniciativas aprovadas e executadas pelo Pibex, que tiveram as comunidades rurais como público beneficiário de suas ações. Dentre as 38 ações executadas no espaço rural, 28 foram desenvolvidas junto a comunidades e grupos de agricultores familiares. Os proponentes de projetos para a agricultura familiar foram os colegiados dos cursos de Engenharia Agronômica (10 projetos), Medicina Veterinária (6 projetos), Zootecnia (5 projetos), Engenharia Agrícola (6 projetos) e Medicina (1 projeto). Constata-se que a extensão universitária para a agricultura familiar realizada pelo Pibex se dá, predominantemente, por meio da atuação de docentes e estudantes das Ciências Agrárias, tendo em vista que 37 dos 38 projetos foram desenvolvidos por cursos dessa área.

Além das Agrárias, é possível identificar uma relação mais próxima com o rural por parte das Ciências Naturais e das Ciências da Saúde, com destaque para Medicina e Enfermagem, pois houve algumas iniciativas que se voltaram para esse meio. As linhas temáticas de atuação dos projetos, detalhadas no Quadro 1, demonstram essa questão.

Quadro 1 - Distinção de linhas temáticas dos projetos PIBEX para o rural

\begin{tabular}{|c|c|c|}
\hline \multicolumn{3}{|c|}{ Projetos PIBEX para o rural conforme linha temática } \\
\hline Ano & Linha temática & $\mathrm{N}^{\circ}$ de projetos \\
\hline \multirow{5}{*}{2016} & Desenvolvimento Rural & 5 \\
\hline & Promoção da Saúde & 2 \\
\hline & Inclusão produtiva e desenvolvimento regional & 1 \\
\hline & Meio Ambiente e Recursos Naturais & 2 \\
\hline & Ciência, Tecnologia e Inovação para a inclusão social & 1 \\
\hline \multirow{3}{*}{2017} & Desenvolvimento Rural & 9 \\
\hline & Meio Ambiente e Recursos Naturais & 2 \\
\hline & Ciência, Tecnologia e Inovação para a inclusão social & 2 \\
\hline \multirow{4}{*}{2018} & Desenvolvimento Rural & 10 \\
\hline & Promoção da Saúde & 2 \\
\hline & Meio Ambiente e Recursos Naturais & 1 \\
\hline & Educação & 1 \\
\hline
\end{tabular}

Fonte: Os autores (2019) baseados nos dados da Direx/Proex.

A maior parte das propostas enquadra-se na linha de Desenvolvimento Rural, com 24 projetos, que representam $63 \%$ de todas as iniciativas para o rural nos três anos analisados. 
Em seguida, aparece Meio Ambiente e Recursos Naturais, com cinco propostas aprovadas, e Promoção da Saúde, com quatro. Apenas uma iniciativa nesse período levou ações de Educação para as comunidades rurais. Esse dado é um indicador preocupante, tendo em vista que o rural tem sido pouco percebido como um espaço para o desenvolvimento de ações extensionistas nessa área.

A extensão universitária que a Univasf vem desenvolvendo junto a agricultores familiares ao longo do triênio dos projetos Pibex em análise se caracterizou por ações voltadas à produção e envolve conhecimentos essencialmente das Ciências Agrárias. Estes projetos atuam junto aos agricultores familiares em propriedades localizadas nas proximidades da Univasf. Tais ações envolvem a participação de docentes, estudantes e alguns parceiros externos, como outras Instituições de Ensino Superior (IES), centros de pesquisa, organizações governamentais e não governamentais.

Identificou-se que estes projetos, de maneira geral, tinham como propósito possibilitar aos agricultores familiares a oportunidade de aprimoramento de técnicas empregadas na produção, gerando diversificação das atividades e/ou melhoria na renda das famílias. Essas ações muito se aproximam do produtivismo difusionista de Rogers (1983), como demonstra o relato de um docente, coordenador de um dos projetos: "a gente pensa na extensão voltada à comunidade mesmo. Então, é transferir o conhecimento da universidade pra comunidade, no anseio de resolver algum problema que a gente identifica" (Docente 1, 2019).

Depoimentos semelhantes mostram que ainda predomina entre os extensionistas a concepção de que a universidade é fonte de conhecimento e precisa transferir este conhecimento ao agricultor. Entretanto, verificou-se que, mesmo com o direcionamento à atividade produtiva, nem todos os projetos adotaram as metodologias características do enfoque difusionista nas ações extensionistas. Há tanto propostas de atuação que se utilizam de metodologias participativas quanto iniciativas com características assistencialistas. No caso desta última, considerando-se a análise documental, manifesta-se em número reduzido. Isso demonstra que a ação assistencialista ainda é presente nas iniciativas de extensão universitária, como mostra o relato de um estudante envolvido em um dos projetos:

Eu me sinto na obrigação de ajudar essas pessoas pra que elas tenham assistência, pra que consigam obter resultado com sua pequena produção, pra ter seu sustento, pra se alimentar e pra o excedente eles conseguirem comercializar e ter uma renda. Eu vejo uma possibilidade de ajudar o próximo. (Estudante 1, 2019). 
Não há uma intencionalidade em prestar um serviço assistencialista, mas a ocorrência desse enfoque é evidente e presente nas práticas extensionistas realizadas junto às comunidades. Um grande risco das ações com esse caráter é que, após a conclusão do projeto, a comunidade volte à mesma condição do momento anterior à intervenção extensionista. Métodos assistencialistas não proporcionam aos participantes o saber transformador pelo qual devem se guiar as atividades extensionistas.

Carbonari e Pereira (2007, p. 25) criticam o assistencialismo na extensão universitária, segundo elas, "as atividades extensionistas foram muito criticadas pelo caráter assistencialista, paternalista e domesticador de comunidades que marcou a história da extensão no Brasil". Entretanto, Coelho (2014, p. 114) faz ressalvas às ações de extensão universitária assistencialista junto a "grupos em situação de grande vulnerabilidade" dadas as dificuldades de se promover um trabalho com mobilização social, envolvimento e participação criativa. Esta foi uma realidade verificada em muitas comunidades de agricultores familiares envolvidas nas ações do Pibex.

Percebe-se que houve uma mudança na apresentação das metodologias de trabalho dos projetos voltados ao rural no período analisado. Em 2016, não havia menção explícita às metodologias participativas de extensão rural nas propostas dos projetos. Em 2017 e 2018, seis projetos em cada ano citaram que as metodologias participativas seriam adotadas nas atividades. O restante apresentou propostas de transferência de tecnologia e capacitação, entre outras, o que indica que, mesmo com o incremento de iniciativas de cunho participativo, têm sido muito expressivas as propostas explicitamente difusionistas.

No entanto, a análise aponta para um incremento em direção a uma participação mais ativa das comunidades envolvidas nas ações de extensão universitária da Univasf. De acordo com relatos de agricultores familiares, constata-se a relação dialógica entre academia e comunidades, evidenciando o enfoque participativo como orientador destas iniciativas.

O curso é bem interessante, porque a professora ensina aquilo que ela veio ensinar, mas também tem a troca de ideias. Tem a experiência da roça, do homem que cria, do campo que eles também não sabiam. São práticas que a gente criou. É de quem mora aqui. De quem não estudou. O interessante que teve a troca de ideias. Ela ensinou aquilo que tinha que ensinar pra gente, mas também ouviu muita coisa que a gente fazia aqui e que eles também não sabiam. (Agricultor Familiar 1, 2019). 
Além de identificar que as relações entre a Univasf e as comunidades rurais se dão a partir de diferentes enfoques metodológicos, foi possível perceber outros aspectos que permeiam a atividade extensionista. A atuação na extensão contribui para a formação cidadã do estudante, renova as práticas de ensino em sala de aula e melhora a relação professor/aluno, aspectos relevantes apontados em outras pesquisas (CASTRO, 2004). A extensão também pode ser um meio de retroalimentação com a pesquisa, na medida em que as atividades são realizadas de forma integrada, como preconiza o conceito da indissociabilidade entre ensino, pesquisa e extensão. Entretanto, essa interação nem sempre ocorre e o que se vê são ações extensionistas isoladas, que carecem muitas vezes de reflexões mais aprofundadas.

Outra constatação é que os agricultores familiares acreditam que a universidade pode colaborar para melhorar a vida das comunidades rurais por meio da disseminação do conhecimento científico. A relevância dessa interação entre academia e sociedade externa é apontada por Freitas, Marinho e Aristide (2018) em relação às intervenções junto a agricultores familiares e por Castro (2004) ao tratar de iniciativas extensionistas promovidas pela área de saúde. Essa percepção por parte dos agricultores familiares envolvidos na pesquisa fica evidente nos depoimentos de agricultores: "Participei pra aprender mesmo. Universidade a gente sempre acha que vai vir com novos conhecimentos. [...] Tem muita gente que fica conversando, mas eu absorvi bastante dessas coisas do curso (Agricultor Familiar 2, 2019).

Apesar de lidarem com fatores adversos, como limitação de tempo e recursos escassos, os projetos Pibex voltados para a agricultura familiar, no geral, alcançam os objetivos a que se propõem, interagindo com os conhecimentos dos agricultores e possibilitando o diálogo da Universidade com as comunidades. Essas dificuldades enfrentadas por extensionistas da Univasf são comuns a outras Instituições de Ensino Superior (CASTRO, 2004; CARBONARI; PEREIRA, 2012). Mas os esforços da comunidade acadêmica, dos parceiros e das próprias comunidades beneficiadas demonstram que essa é a direção a seguir para democratizar o conhecimento, possibilitando, assim, a emancipação das populações.

A abordagem difusionista ainda permeia as ações extensionistas de maneira geral. Particularmente na extensão rural universitária nas Ciências Agrárias da Univasf essa abordagem é predominante por razões históricas inerentes à forte influência do difusionismo produtivista da Revolução Verde e de tradições metodológicas da extensão rural brasileira (MARINHO; FREITAS, 2015). Entretanto, mesmo nos projetos de orientação difusionista do 
Pibex, constata-se que, para além dos métodos empregados, a interação entre agricultores familiares e comunidade acadêmica possibilita a troca de informações e a construção de relações de cooperação.

No caso dos projetos orientados pela abordagem participativa, constata-se haver um reconhecimento entre ciência e saberes populares. Ela se aproxima do que Coelho (2014) denomina de perspectiva etnocientífica na medida em que possibilita a valorização explícita das possibilidades da troca de saberes, bem como o reconhecimento e a valorização dos saberes populares. Ações extensionistas desenvolvidas nessa perspectiva promovem a consolidação da indissociabilidade entre ensino, pesquisa e extensão, conforme preconiza o Forproex.

\section{Considerações finais}

A institucionalização da Extensão Universitária na Univasf está fortemente relacionada à constituição dos programas internos de incentivo à atividade extensionista, iniciada com o Pibin e desempenhada pelo Pibex. Constatou-se que o Pibex tem se constituído no principal instrumento de promoção e democratização efetiva das ações extensionistas no âmbito da Univasf.

Demonstrou-se, por meio desse trabalho, que tem aumentado o interesse de docentes e estudantes pela prática das ações extensionistas no meio rural. Constatou-se que as principais ações extensionistas apoiadas pelo Pibex envolvem aspectos produtivos no âmbito das Ciências Agrárias e ainda são muito orientadas pelo enfoque difusionista, devido a uma tradição da extensão rural nessa área de conhecimento. Embora pareça contraditório, mesmo com essa orientação metodológica, tais espaços também têm possibilitado interações entre comunidade acadêmica e agricultores familiares, que contribuem com a formação cidadã, a promoção da construção de conhecimento e pró-atividade frente às situações e demandas sociais que se apresentam no fazer da extensão universitária e extensão rural.

A presente pesquisa também permitiu identificar que agricultores familiares anseiam por novos saberes e esperam da Universidade mais oportunidades de interação que lhes possibilitem acesso à informação e à troca de saberes. Essa troca de conhecimentos, embora já aconteça na Univasf, precisa ser ampliada de modo que a Universidade possa promover a formação cidadã e a superação das desigualdades sociais. 


\section{Agradecimentos}

Ao CVT Sertão Agroecológico, apoiado pela Chamada MCTIC/MAPA/MEC/SEAD - Casa Civil/CNPq nº 21/2016.

\section{Referências}

BARROSO, K. A.; CAPUCHO, A. S.; FREITAS, H. R. Levantamento de doenças foliares em hortas urbanas de Petrolina-PE. Extramuros: Revista de Extensão da UNIVASF, Petrolina, v. 5, n. 2, p. 164-181, 2017. Disponível em: http://www.periodicos2.Univasf.edu.br/index.php/extramuros/article/view/1065/719. Acesso em: 10 jun. 2019.

BRASIL. Constituição (1988). Constituição da República Federativa do Brasil. Brasília, DF: Senado Federal, 1988.

BRASIL. Lei da Agricultura Familiar. Lei no 11.326, de 24 de julho de 2006. Estabelece as diretrizes para a formulação da Política Nacional da Agricultura Familiar e Empreendimentos Familiares Rurais. Brasília, DF, 2006.

BRASIL. Ministério da Educação. Lei de Diretrizes e Bases da Educação. Lei n ${ }^{\circ}$ 9.394, de 23 de dezembro de 1996. Estabelece as diretrizes e bases da educação nacional. Brasília, DF 1996.

BRASIL. Ministério da Educação. Plano Nacional de Educação. Lei n ${ }^{\circ}$ 13.005, de 26 de junho de 2014. Aprova o Plano Nacional de Educação - PNE e dá outras providências. Brasília, DF, 2014.

BRASIL. Lei n ${ }^{\circ} 10.473$, de 27 de junho de 2002. Institui a Fundação Universidade Federal do Vale do São Francisco. Brasília, DF, 2002.

BRASIL. Ministério da Educação. Portaria n 1.350 , de 14 de dezembro de 2018. Estabelece as diretrizes para a extensão na educação superior brasileira. Disponível em:

http://www.in.gov.br/materia/-/asset_publisher/Kujrw0TZC2Mb/content/id/55444656.

Acesso em: $1^{\circ}$ jan. 2019.

CARBONARI, M. E. E.; PEREIRA, A. C. A extensão universitária no Brasil, do assistencialismo à sustentabilidade. Revista de Educação UFPB, João Pessoa, v. 10, n. 10. 2007, p. 27. Disponível em:

http://www.pgsskroton.com.br/seer/index.php/educ/article/view/2133/2030. Acesso em: 15 ago. 2018.

CASTRO, L. M. C. A universidade, a extensão universitária e a produção de conhecimentos emancipadores. In: A extensão universitária e a produção de conhecimentos emancipadores (ainda existem utopias realistas). 2004. Disponível em: http://www.anped.org.br/sites/default/files/t1111.pdf. Acesso em: 15 ago. 2018. 
COELHO, F. M. G. Questões pedagógicas, éticas e políticas da extensão universitária. In: A arte das orientações técnicas no campo: concepções e métodos. Viçosa: Editora UFV, 2014. p. 169-188.

FORPROEX. Política Nacional de Extensão Universitária. 2012. Disponível em: https://www.ufmg.br/Proex/renex/images/documentos/2012-07-13-Politica-Nacional-deExtensao.pdf. Acesso em: 15 maio 2019.

FREITAS, H. R.; MARINHO, C. M.; ARISTIDE, P. Extensão universitária e agricultura urbana e periurbana: construção e troca de saberes para o desenvolvimento sustentável no semiárido brasileiro. 2018. In: CONGRESO INTERNACIONAL DE EDUCACIÓN SUPERIOR - UNIVERSIDAD, 11., 2018, Havana. Anais [...]. Cuba: La Havana, 2018.

INCROCCI, L. M. M. C.; ANDRADE, T. H. N. O fortalecimento da extensão no campo científico: uma análise dos editais Proext/MEC. Revista Sociedade e Estado, Brasília, v. 33, n. 1, p. 189-214, jan./abr. 2018. Doi: 10.1590/s0102-699220183301008.

INSTITUTO BRASILEIRO DE GEOGRAFIA E ESTATÍSTICA. Censo Agropecuário 2006. Disponível em: https://sidra.ibge.gov.br/Tabela/1118\#resultado. Acesso em: 10 jun. 2019.

LEÃO, E. L. S.; MOUTINHO, L. M. G. O arranjo produtivo local de fruticultura irrigada do Vale do Submédio do São Francisco como objeto de política. RACE - Revista de

Administração, Contabilidade e Economia, Maceió, v. 13, n. 3, p. 829-857, set. 2014.

Disponível em: http://editora.unoesc.edu.br/index.php/race/article/view/4611. Acesso em: 2 jan. 2019.

MARINHO, C. M. et al. Por que ainda falar e buscar fazer extensão universitária?

Extramuros: Revista de Extensão da UNIVASF, Petrolina, v. 7, n. 1, p. 121-140, 2019.

Disponível em:

http://www.periodicos2.univasf.edu.br/index.php/extramuros/article/view/1310/7. Acesso em: 16 out. 2019.

MARINHO, C. M; FREITAS, H. R. Utilização de metodologias participativas nos processos de Assistência Técnica e Extensão Rural (ATER): fundamentos teórico-práticos.

Extramuros: Revista de Extensão da UNIVASF, Petrolina, v. 3, n. 3, p. 10-28, 2015.

Disponível em:

http://www.periodicos2.univasf.edu.br/index.php/extramuros/article/view/744/464. Acesso em: 16 out. 2019.

OLIVEIRA, L. M. S. R.; OLIVEIRA, L. S.; VIEIRA, D. D. A trajetória da extensão universitária e os seus desafios atuais. In: EYSEN, A. (org.). Tecendo manhãs: educação, saberes e experiências no território do Sisal. Itabuna: Mondrongo, 2018. p. 17-33.

RODRIGUES, C. M. Conceito de seletividade de políticas públicas e sua aplicação no contexto da política de extensão rural no Brasil. CC\&T, Brasília, v. 14, n. 1, p. 113-154, jan./abr. 1997. Disponível em:

http://seer.sct.embrapa.br/index.php/cct/article/view/8963/5075. Acesso em: 2 maio 2019.

ROGERS, E. M. Diffusion Of Innovations. 3. ed. New York: The Free Press, 1983.

SANTIAGO, A. M. dos S. (coord.). Relatório de Gestão 2004-2008. Petrolina: UNIVASF, 2008. 
SILVA, J. C.; SILVA, A. C. G C. Um diagnóstico das práticas de medição de desempenho utilizadas pelas empresas exportadoras de frutas do Vale do São Francisco. Revista

Principia, João Pessoa, n. 32, p. 43-50, dez. 2016. Doi: http://dx.doi.org/10.18265/151703062015v1n32p43-50.

SIQUEIRA, R. Caravana agroecológica do Semiárido Baiano: um relato do contexto histórico e contemporâneo dos caminhos das águas do Rio São Francisco. Extramuros: Revista de Extensão da UNIVASF, Petrolina, v. 5, n. 2, p. 5-21, 2017. Disponível em:

http://www.periodicos2.UNIVASF.edu.br/index.php/extramuros/article/view/1051/708.

Acesso em: 14 jan. 2019.

TRIVIÑOS, A. N. S. Introdução à pesquisa em Ciências Sociais: a pesquisa qualitativa em educação. São Paulo, Atlas: 1987.

UNIVERSIDADE FEDERAL DO VALE DO SÃO FRANCISCO. Resolução n 4/2017. Disponível em: http://portais.Univasf.edu.br/Proex/banco-de-dados/camara-deextensao/2017/resolucao_4-2017.pdf. Acesso em: 4 marc. 2019.

UNIVERSIDADE FEDERAL DO VALE DO SÃO FRANCISCO. Resolução n⿳0 8/2015.

Disponível em: https://sig.Univasf.edu.br/sigrh/public/colegiados/filtro_busca.jsf. Acesso em: 2 jan. 2019.

Submetido em 28 de junho de 2019.

Aprovado em 27 de outubro de 2019. 